\title{
COMPARISION OF FOUR FABRICS FOR FILTERING TURBID WATER IN A TWO STAGE CROSS-FLOW FILTER
}

\author{
Goldie Davis $^{1 *}$, Edwin Ekwue ${ }^{2}$ and Vincent Cooper ${ }^{3}$ \\ ${ }^{1,2,3}$ Faculty of Engineering, The University of the West Indies, Trinidad \\ ${ }^{1}$ Email: goldie.davis@my.uwi.edu* \\ ${ }^{2}$ Email: Edwin.Ekwue@sta.uwi.edu \\ ${ }^{3}$ Email: vincent.cooper@sta.uwi.edu
}

\begin{abstract}
Surface water treatment plants in Trinidad are incapable of filtering highly turbid water. Water treatment operations are shut down whenever turbidity levels rise during or after rainfall. The aim of this research is to determine the physical properties of linen, burlap, crepe-backed satin and cotton fabrics and to compare their efficiencies as filter media for reducing turbidity in water. Scanning electron microscopy was used to generate images of each fabric. Fabric weave type was determined. Inter-yarn pore sizes, inter-fiber pore sizes, warp and weft spacings, warp and weft diameters and thicknesses were measured using ImageJ. Based on the properties examined, and execution of crossflow filtration and perpendicular filtration tests, linen was the chosen fabric filter medium. Surface profilometry resulted in linen having the roughest surface of $685.5 \mu \mathrm{m}$ and the largest maximum profile height of $3632.4 \mu \mathrm{m}$. Linen's inter-yarn and inter-fiber pore sizes were $41.98 \mu \mathrm{m}$ and $22.37 \mu \mathrm{m}$ respectively. This fabric had warp and weft spacings of $400 \mu \mathrm{m}$ and $700 \mu \mathrm{m}$ respectively and was $400.39 \mu \mathrm{m}$ thick. Measurements also revealed warp and weft diameters of $13.26 \mu \mathrm{m}$ and $14.96 \mu \mathrm{m}$ respectively. Linen had a high tensile strength of $402 \mathrm{~N}$. Linen, had a hopsack plain weave and was tightly woven; it was $95.16 \%$ porous with a sediment retention capacity of $71 \%$. Linen is a fabric material that could prove to be a very good filter medium. Also, Acono River water turbidity levels measured ranged from 2.47NTU to $23.93 \mathrm{NTU}$. Soil types contained in the turbid water were gravels, sand and silt varying from $25 \mathrm{~mm}$ to $0.075 \mathrm{~mm}$ in size.
\end{abstract}

Keywords: Fabric, Filter, Linen, Turbidity, Water Treatment.

https://doi.org/10.47412/NEGV5542

\section{Introduction}

The unavailability of a supply of clean drinking water is one of the numerous challenges experienced globally. Worldwide, 2.1 billion people lack access to a supply of safe drinking water. Many people die from water borne diseases like cholera and typhoid fever with diarrhoea being the leading cause of death in children with as many as 1.5 million deaths per year [1]. Safe drinking water not only sustains life but prevents diseases and access to it is a basic human right [2].

All waters exposed to the atmosphere and which are subject to surface runoff are defined as surface water. Running surface water supplies are rivers and streams [3]. Worldwide, 159 million people rely on untreated surface water. Surface water provides $60 \%$ of water supply in Trinidad and Tobago [4]. Surface water treatment plants (WTPs) owned and operated by the Water and Sewerage Authority (WASA) extract water from rivers and dams and make it potable for human consumption but high turbidity is a recurring problem experienced. Water turbidity increases when there is heavy rainfall and during the rainy season from June 


\section{The International Conference on Emerging Trends in Engineering and Technology (IConETech-2020) Faculty of Engineering, The UWI, St. Augustine | June $1^{\text {st }}-5^{\text {th }}, 2020$}

to December. The filters are incapable of filtering the turbid water and become clogged. When this happens, the WTP is shut down until turbidity levels decrease. During this time, the filters are backwashed. WTP shut down results in both a loss in water production and a disruption in supply to customers.

One such plant is the Acono Water Treatment Plant (WTP), in Maracas, Trinidad which extracts approximately $2000 \mathrm{~m}^{3}$ of water per day from the Acono River for treatment. This plant follows a process of conventional water treatment in which the extracted water from the river is sent to the clarifier then the filter and finally to the clearwell for disinfection. When river water turbidity is high, approximately $15 \mathrm{NTU}$, the plant is shut down because of the incapability of the rapid gravity filter to filter this level of turbidity. The rapid gravity filter consists of $1.8 \mathrm{~m}$ of sand [5]. As the turbid water flow is perpendicular to the media, particles become suspended on its surface and within the media. The filter media is no longer capable of filtering water at 15NTU and cake build-up takes place causing clogging and WTP operations are stopped. Moreover, to avoid filter clogging, when turbidity levels begin increasing, the operations are immediately shut down at the plant [6].

Generally, a filter is defined as a device in which mechanical separation of the components of a solution is separated from a liquid without a change in phase by passing through a permeable barrier [7]. In rapid gravity filtration, the water level or pressure head above the filter forces water through the sand media [8]. Conversely, in cross-flow filtration (CFF), because the flow is parallel to the filter medium, there is little cake build-up [9]. The practice of cross-flow microfiltration is prominent in Vinification, the process of wine production since crude wine or unfinished wine consists of solutes $(\leq 1 \mathrm{~nm})$, colloids (between $1 \mathrm{~nm}$ and $1 \mu \mathrm{m})$ and particles $(\geq 1 \mu \mathrm{m})$ [9]. Limpidity is both a primary and visual quality in wine which is checked for by customers. Wine limpidity is measured by turbidity and must be less than 2NTU after filtration [9]. Tangential filters are used after fermentation and before bottling in Vinification, resulting in the improved taste of wine as yeast and bacteria are removed [9]. Despite CFF not being entirely new, the process has not been applied to water treatment in WASA. If CFF is implemented in its water treatment process, then there will be no need to shut down operations and filters will not have to be backwashed.

A filter medium is described as the heart of a filter [10]. Essential characteristics of a filter medium are that it must be permeable, inert, easy to clean, hard and durable, impurity free and insoluble in water [11]. Fabric filtration, on the other hand is similar to rapid gravity filtration and CFF as solids are retained on the fabric medium [12]. Fabrics are most commonly used as a filter medium in fine size filtration. Fabric filter media is characterized by the number of weaves, mesh size, yarn size and mesh type. Fabric has the ability to withstand high working pressures [13]. Cloth filtration is used in wastewater treatment, for example, the San Fernando Wastewater Treatment Plant in South Trinidad uses five rotating disc filters covered with cloth [14]. In Matlab, Bangladesh, sari cloth was used for filtering water. The sari cloth was folded four times, thereby resulting in $\geq 99 \%$ bacteria removal and $48 \%$ cholera reduction [15].

Furthermore, filtration is an important aspect in the provision of clean drinking water as it reduces turbidity. Turbidity is the result of chemical and biological particles suspended in water and blocks the passage of light passing through water. It is hazardous to water safety and deteriorates the aesthetic quality of water. Turbidity is therefore an indicator of pathogenic microorganisms present in water and determines how clear water is. A milky white, red- brown, muddy or a black suspension means that water is turbid. A turbidity of 4NTU or greater is visible to the naked eye and is a common index used for measuring and controlling filtration efficiency. The upside to turbidity is that it can be continuously monitored. Acceptable turbidity levels are $\leq 5 \mathrm{NTU}$. Above 5NTU can result in impacts on disinfection [16].

This paper focuses on the investigation of physical properties of linen, crepe-backed satin, burlap and cotton fabric. The properties measured include surface roughness, thickness weave type, warp and weft spacing, warp and weft diameters, inter-yarn and inter-fibre pore sizes via surface profilometry and scanning electron microscopy. Inter-yarn pores sizes were used to calculate porosity and fabric tensile strength was also investigated. The respective properties will aid in selecting a fabric filter medium which is suitable for use 
as a filter medium in a two stage cross-flow filter. Water turbidity levels at the Acono River were also measured so as to determine turbidity levels to be filtered in the two-stage cross flow filter. Further to this, soil type and particle sizes contained in the turbid water were also determined.

\section{Materials and Methods}

\subsection{Fabric Materials}

Linen, one of the oldest fibres, made from the flax plant is said to be very strong and even stronger when wet [17]. Its fibres have low cellulose content and are short. It is resistant to alkalis and is easily deteriorated by acids. This material is very durable and was used in wrapping mummies in Egyptian tombs. Other properties of linen are that it is a good absorbent and is smooth. Burlap is a coarse heavy fabric, manufactured from jute, hemp or cotton. It is commonly used in making curtains, upholstery and wall coverings [17]. Cotton, on the other hand, is a natural fibre used for manufacturing high-quality materials. The long, fine threads are high in strength. Crepe-backed satin is a double-sided fabric, one side being crepe and other satin. Crepe-backed satin fabric has a dull surface which is also crinkled and is either woven or knitted. Its satin side is woven from cotton, silk and artificial fibres [18]. These fabric types were chosen for investigation because they are locally and readily available as well as affordable.

\subsection{Laboratory Testing of Fabric Materials}

Experimental testing of the various fabric materials began with surface profilometry. Surface roughness and maximum profile heights of fabric were tested using a Mitutoyo Surftest SJ.400 [20]. This apparatus is a portable measuring instrument used for measuring surface roughness and maximum profile heights. It consists of a stylus which moves over the surface being tested and quantifies the roughness and profile heights [19]. Series surface profilometer was set at surface roughness standard Ra 116 $\mu \mathrm{in} .(2.94 \mu \mathrm{m})$ and Rmax $396 \mu$ in. $(9.3 \mu \mathrm{m})$. Fabric of dimension, $25.4 \mathrm{~cm} \times 5.08 \mathrm{~cm}$ was set up on the surface profilometer and the stylus was allowed to move back and forth over the surface of the fabric. Five readings each for surface roughness, $\mathrm{Ra}$ and maximum profile height $\mathrm{Rz}$, were measured and an average value calculated. Average surface roughness, $\mathrm{Ra}$, is the arithmetic average of the absolute values of the profile heights over the evaluation length $\mathrm{L}$ which is twice the cutoff length, $K \mathrm{c}$ of $0.001 \mathrm{~mm} \times 5$. Values of fabric surface roughness ranged from as low as $442.5 \mu \mathrm{m}$ to as high as $821.7 \mu \mathrm{m}$ respectively. Average profile maximum height, $\mathrm{Rz}$, is the vertical distance of the highest and lowest points [20]. Profile maximum heights ranged from $2507 \mu \mathrm{m}$ to $4228 \mu \mathrm{m}$ respectively. The measured values from the tests are shown in Table 1.

Following this, scanning electron microscopic (SEM) test was performed using a Phillips Scanning Electron Microscope 515 [21]. A high energy beam of electrons formed an image by illuminating the specimen under the SEM and controlled by using electrostatic and electromagnetic lenses and is used for producing high resolution images and which have a large depth of field, is known as scanning electron microscopy [21]. Fabric sizes of $\approx 1 \mathrm{~cm}$ were dried and coated using a Denton Desk II Cold Sputter Unit, thereby making them conductive so that no charging will occur [21]. The fabric was then placed inside the SEM and images large enough to show pore sizes and yarns were generated for each fabric type and shown in Fig.1.

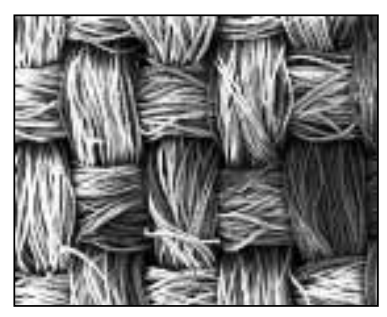

Linen

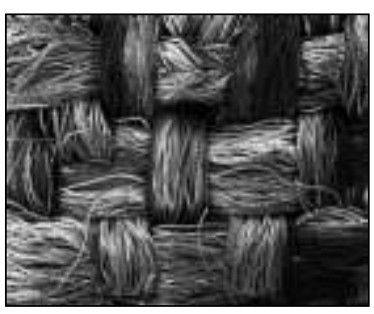

Crepe-backed satin

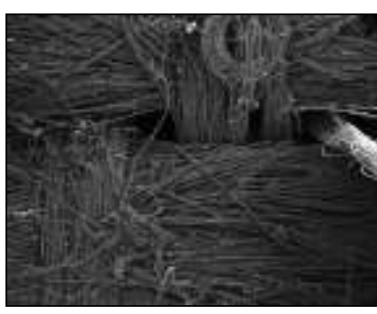

Burlap

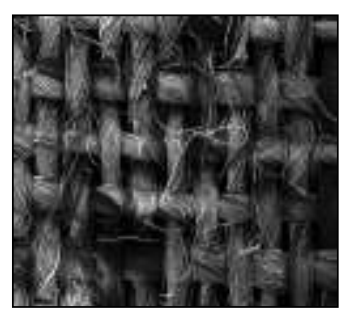

Cotton 
Figure 27: Analysis of Fabric

Table 10: Fabric Properties Measured and Identified

\begin{tabular}{|c|c|c|c|c|}
\hline \multirow{2}{*}{ Property } & \multicolumn{4}{|c|}{ Fabric Type } \\
\cline { 2 - 5 } & Linen & Crepe-backed satin & Burlap & Cotton \\
\hline Inter-yarn pore size $(\mu \mathrm{m})$ & 41.98 & 66.88 & 408.28 & 76.67 \\
\hline Inter-fiber pore size $(\mu \mathrm{m})$ & 22.37 & 27.99 & 41.88 & 11.36 \\
\hline Inter-yarn porosity $(\%)$ & 95.16 & 93.90 & 98 & 95.32 \\
\hline Fabric thickness $(\mu \mathrm{m})$ & 400.39 & 507.08 & 1132.81 & 191.89 \\
\hline Warp spacing $(\mu \mathrm{m})$ & 441.67 & 528.75 & 1443.58 & 496.57 \\
\hline Weft spacing $(\mu \mathrm{m})$ & 741.67 & 703.66 & 2278.85 & 455.88 \\
\hline Warp diameter $(\mu \mathrm{m})$ & 13.26 & 17.52 & 14.42 & 11.58 \\
\hline Weft diameter $(\mu \mathrm{m})$ & 14.96 & 18.06 & 28.85 & 11.26 \\
\hline Fabric tensile strength $(\mathrm{N})$ & 402 & 194 & 462 & 211 \\
\hline Surface roughness $(\mu \mathrm{m})$ & 685.50 & 634.64 & 554.82 & 554.32 \\
\hline Maximum profile height $(\mu \mathrm{m})$ & 3632.40 & 2854.20 & 2808 & 2741.60 \\
\hline Weave type & Hop-sack plain & Satin & Plain & Plain \\
\hline
\end{tabular}

From the respective images, fabric thickness, warp and weft spacing, warp and weft diameter, inter-yarn and inter-fibre pore sizes were measured using ImageJ. ImageJ is a software programme written in Java. It can be used for measuring lengths and diameters in micrometres using scanning electron microscopic images [22].

Fabric weave type was determined from image inspection and fabric inter-yarn porosity was calculated using the equation:

$$
\text { Porosity }=\left(\mathrm{p}_{1} \mathrm{p}_{2}\right) \div\left\{\left(\mathrm{p}_{1}+\mathrm{d}_{1}\right)\left(\mathrm{p}_{2}+\mathrm{d}_{2}\right)\right\}
$$

While,

$$
\mathrm{p}_{1}=\text { Warp spacing, } \mathrm{p}_{2}=\text { Weft spacing, } \mathrm{d}_{1}=\text { Diameter of warp yarn, } \mathrm{d}_{2}=\text { Diameter of weft yarn [23] }
$$

In addition, tensile tests along the warp direction for each fabric were executed using a Tinius Olsen Universal Testing Machine, as the warp yarns tend to be stronger than the weft yarns. [24]. Each fabric was cut into dumbbell shapes $18.5 \mathrm{~cm}$ long, $2 \mathrm{~cm}$ wide and $1.4 \mathrm{~cm}$, inner width. This is the standard sample size recommended for tensile testing when using the Tinius Olsen Universal Testing Machine. The fabric was set up on the machine and subjected to a tensile strength of $515 \mathrm{~N}$. An average tensile strength for each fabric was calculated. Table 1 shows the measured physical properties of the fabrics. 


\subsection{Source of River Water and Soil Samples}

Two samples of turbid water were used. The first sample was created from a mixture of rendering sand and pipe water. These turbid mixtures were used in the experiments involving the sediment transport channel. The second sample was obtained from the Acono River. Samples of raw water and soil were collected from the Acono River, $10.71^{\circ} \mathrm{N}$ and $61.39^{\circ} \mathrm{W}$, in Maracas, North Trinidad. This has an elevation of $108 \mathrm{~m}$ and $710 \mathrm{~m}$ distance as the crow flies, upstream of the Acono Water Treatment Plant. The measured water temperature at the site was $22^{\circ} \mathrm{C}$. Over a five day period, water samples were filled in $1000 \mathrm{ml}$ bottles before and during rainfall. Each sample collected was at distance of $14.3 \mathrm{~m}$ apart, adding to a total distance of $42.9 \mathrm{~m}$. The samples were taken to the laboratory and turbidity was measured using a Hach $2100 \mathrm{~N}$ Turbidimeter [25]. Soil samples the same distance apart were collected and mechanical sieve analysis performed to determine soil sizes and types according to the ASTM D422-63 (2007) Standard Test Method for Particle-Size Analysis of Soil [26].

\subsection{Sediment Transport Channel (STC) for Cross-Flow Filtration}

An S8MkII Sediment Transport Channel, $1.5 \mathrm{~m}$ x $0.3 \mathrm{~m}$ was used for preliminary testing of cross-flow filtration using burlap and linen fabric filter mediums [27]. Changes were made to the STC to include a fabric filter medium. Two pieces of pitch pine wood were each cut into dimensions $101 \mathrm{~cm} \times 1.27 \mathrm{~cm} \times 3.8 \mathrm{~cm}$. This was to create a base on which the filter medium rested and was attached onto the side walls of the STC from the discharge end using silicone adhesive. After, a rectangular weir of dimensions, $7.77 \mathrm{~cm} \times 1.27 \mathrm{~cm} \times 3.81 \mathrm{~cm}$ was prepared. The rectangular weir was attached onto the front end of the base and prevented turbid water from entering the area where the filtrate collects. Then, an over-shot weir consisting of an opening of diameter $1.27 \mathrm{~cm}$ was installed on the discharge end. PVC pipe, $1.27 \mathrm{~cm}$ in diameter and $61 \mathrm{~cm}$ long with a $1.27 \mathrm{~cm}$ control valve was attached to the over-shot weir. This provided a channel through which the filtrate was emptied for testing. A bucket was used as a clear well for filtrate collection. The water which was not filtered re-entered the collecting/settling tank. A wire mesh, $91 \mathrm{~cm} \times 30.5 \mathrm{~cm}$ was cut and attached onto the underside of burlap fabric and then the same was done for linen fabric of the same dimensions. A turbid water mixture was created using rendering sand. Inclusion of the fabric filter medium in the STC is shown in Fig.2. Note the red arrow indicates the direction of flow of turbid water over the surface of the fabric filter medium in the warp direction.

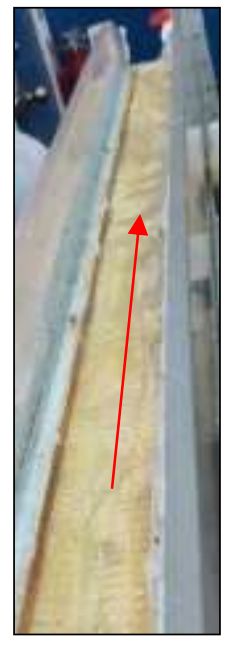

Figure 28: Plan View showing Fabric Filter Medium set up in an S8MkII Sediment Transport Channel

\subsection{Filtration using Burlap and Linen Fabric Filter Medium}

On assessing the properties of different fabric in Table 1, it was found that the two most feasible fabrics were burlap and linen. The fabric types were selected because they were the thickest and had the largest tensile strengths. They were therefore subjected to cross-flow filtration using turbid water mixtures in the S8MkII 
sediment transport channel. Testing was done three times for each fabric type and an average calculated and shown in Table 2 below.

Table 11: Turbidity measured in Sediment Channel Cross-flow Filtration

\begin{tabular}{|c|c|c|}
\hline \multirow{2}{*}{ Fabric Type } & \multicolumn{2}{|c|}{ Average Turbidity (NTU) } \\
\cline { 2 - 3 } & Before filtration & After filtration \\
\hline Burlap & \multirow{2}{*}{137} & 118 \\
\cline { 3 - 3 } & & 13 \\
\hline
\end{tabular}

Afterwards, linen of dimension $5 \mathrm{~cm}$ x $5 \mathrm{~cm}$ was held over a $1000 \mathrm{ml}$ beaker and turbid water from the Acono River was poured over it. The turbidity of the filtrate was measured and compared to the turbidity of the raw water. A stop watch was simultaneously started and the time taken for the water to soak into the fabric was measured and recorded. Then, the efficiency (Table 3) of linen in terms of sediment retention capacity was calculated using Equation 2 as follows:

$$
\{\text { (Turbidity before - Turbidity after }) \div \text { Turbidity before }\} \times 100 \%
$$

Table 12: Efficiency of Linen Fabric Filter Medium in a Perpendicular Flow

\begin{tabular}{|c|c|c|c|}
\hline \multirow{2}{*}{$\begin{array}{c}\text { Sample } \\
\text { Number }\end{array}$} & Turbidity (NTU) & $\begin{array}{c}\text { Retention Capacity } \\
\text { (\%) }\end{array}$ \\
\cline { 2 - 3 } & Before Filtration & After Filtration & \\
\hline 1 & 11 & 3 & 72.7 \\
\hline 2 & 11 & 3 & 72.7 \\
\hline 3 & 10 & 3 & 70.0 \\
\hline 4 & 10 & 3 & 70.0 \\
\hline Average & 10.5 & 3.0 & 71.0 \\
\hline
\end{tabular}

\section{Results and Discussion}

The average values of the measured physical properties for each fabric type are shown in Table 1. Also included is weave type. The properties are tabulated in order of importance to the general characteristics of a filter media. Some of the properties measured and identified in Table 1 are an indication of filter medium characteristics.

Surface roughness can affect the flow of water. Each fabric's surface roughness and profile height are due to the way in which it is woven, i.e. how the warps and wefts interconnect with one another. Weave type is also determined from this. As seen in Table 1, linen had the roughest surface and had the largest maximum profile height, followed by crepe-backed satin. Burlap and cotton possess surface roughness values which did not greatly differ. Material smoothness can also be determined by simply touching each fabric. This is the subjective method of analysing fabric roughness.

Using ImageJ it was deduced that burlap was the thickest fabric and cotton was the thinnest. Linen and crepe-backed satin had similar thicknesses. Fabric thickness is essential since it can affect the quantity of particles retained within the fabric, in addition to inter-fiber pore sizes. In warp spacing burlap and crepe- 
backed satin fabrics was the largest meaning that these two fabrics will be unable to retain particles as they are not tightly woven. Linen had the smallest spacing between its warps. Smaller spacing means that the fabric is more tightly woven.

Similarly, warp and weft diameters are measurements of yarn width. Yarn diameter is critical since it determines filtration flow rate or yield. This is because it affects the amount of open space in the cloth [28]. Burlap and crepe-backed satin had very large warp diameters, with linen being third in line and lastly cotton. The same held for weft diameters. This is a clear indication as to why burlap failed in retaining particles during cross-flow filtration.

Properties of permeability vary according to inter-yarn pore sizes which affect the quantity of particles and water which passes through it i.e. the porosity. Burlap and cotton had the largest inter-yarn pore sizes resulting in porosities of $98 \%$ and $95.32 \%$ respectively. Crepe-backed satin had a porosity of $93.90 \%$ and linen $95.16 \%$ respectively. Again, burlap was extremely porous. Linen consisted of the smallest inter-yarn pore sizes.

The fabrics used in this study were woven fabrics. Woven fabrics are constructed by interlacing yarns. The warps are lengthwise and the wefts or filling yarns are crosswise [29]. Examination of SEM images shown in Fig. 1 revealed that linen is a hop-sack plain weave, crepe-backed satin is a satin weave, whilst burlap and cotton are plain weaves. Plain weaves like burlap and cotton are considered to be the simplest weave construction. The filling yarns are woven alternately over and under the warp yarn. In a satin weave, the warp yarn passed over four to eight weft yarns resulting in a staggered pattern. As for a hopsack plain weave, there were two threads in the warp followed by two threads in the weft [30].

Tensile strength, on the other hand, is a representation of how hard and durable the fabric is. It will be helpful in this study as it gives the researcher an indication of how strong the fabric is, since the tension which the fabric will be subjected to, is the weight of water. Burlap and linen had the highest tensile strengths. Both fabric types were able to withstand tensions of up to $525 \mathrm{~N}$ before bursting. Crepe-backed satin and cotton on the other hand almost immediately tore when subjected to tension of $225 \mathrm{~N}$ and less. The maximum or ultimate tensile stress which burlap withstood was approximately $462 \mathrm{~N}$ and linen is $402 \mathrm{~N}$, slightly less than burlap. Whilst undergoing tensile testing, it was observed that warp yarns of burlap began to slowly unravel. Small tears were also seen forming in linen. Cotton and crepe-backed satin on the other hand, were considered brittle as they exhibited small extensions to fracture. This means that these two fabrics failed the tensile tests. Having compared all four fabric types, cotton and crepe-backed satin had approximately half the tensile strengths of burlap and linen.

After intense fabric analysis, linen and burlap were selected for cross-flow filtration using the sediment transport channel at a pump setting of $0.621 / \mathrm{s}$. These fabric types were selected because they were the thickest and had the largest tensile strengths. The turbidity of the water i.e. the filtrate which passed through the types of fabric was measured. Table 2 indicates that linen proved more successful since a turbidity of 13 NTU was obtained after filtration, as compared to burlap which was 118 NTU. Turbid water levels were as high as $397 \mathrm{NTU}$ before filtration and varied from 119NTU to $11 \mathrm{NTU}$ after filtration. For further comparisons, crepe-backed satin and cotton will be assessed in cross-flow filtration.

Preliminary analysis involved folding the individual fabrics and subjecting it to perpendicular filtration. The fabrics were folded into eight layers, four layers and two layers. A turbid water mixture was created using rendering sand which varied from $295 \mathrm{NTU}$ to $820 \mathrm{NTU}$. Filtrate turbidity ranged from $809 \mathrm{NTU}$ to 286NTU. It was deduced that almost all particles passed through the burlap fabric, whilst some were retained on the surface of crepe-backed satin, cotton and linen fabrics. Again, based on elimination, linen was selected.

Continuous assessment of linen occurred in perpendicular filtration. When turbid water from the Acono River was used, mean water turbidity decreased by less than $50 \%$, i.e. from $10.5 \mathrm{NTU}$ to $3.0 \mathrm{NTU}$. Refer to 
Table 3. A turbidity of 3.0NTU is within World Health Organization drinking water standards. To further test linen's effectiveness in filtration, its mean sediment retention capacity was calculated as $71 \%$. This is also shown in Table 3. During perpendicular filtration, linen took approximately 14.4 seconds to become completely soaked before the water was able to pass through it. A time of 14.4 seconds means that there is a possibility that the fabric, in adherence to its thickness, has a high absorption capacity. Further testing will be able to confirm this.

In converse to fabric analysis, turbidity as well as soil type and sizes were investigated. Rainfall was moderate over a five day period, and there was a change in turbidity levels. Respective samples were collected where there was the least amount of human activity occuring, so as to avoid turbidity being affected by human activity. It was found that the average surface water turbidity over the five day period ranged from $2.47 \mathrm{NTU}$ to $23.93 \mathrm{NTU}$. And particle sizes ranged from $25 \mathrm{~mm}$ to $\leq 0.075 \mathrm{~mm}$, thus being identified as gravel, sand and silt. Emphasis will be placed on particles of sizes $300 \mathrm{~mm}$ and smaller since the larger particles or gravel are considered settleable particles and can be found on the river bed. The other particles which do not easily settle such as the colloids will be focused on in future study.

After comparing and contrasting each fabric property one at a time, an overall analysis was made to select the most appropriate fabric for use as a filter medium. Selection was made based on filter medium characteristics mentioned earlier and the process of elimination. The fabrics were all insoluble and inert in water since there were no changes to the physical composition during experimentation. And they were impurity free since there were no bacteria nor viruses contained in the fabric. Only new fabric materials were used. With respect to cleaning, the fabric could be washed. But in this study, it is recommended that the fabric be replaced since the filter medium will be designed as a cartridge filter which could be easily removed from the cross-flow filter tank.

Hardness and durability, on the other hand can be assessed based on tensile strength. With regard to this characteristic, crepe-backed satin and cotton were easily eliminated. This left behind burlap and linen. Permeability, an essential characteristic was assessed based on inter-yarn pore sizes and inter-fiber pore sizes. Burlap had extremely large inter-yarn pore sizes and inter-fiber pore sizes. This was further proven when during filtration in the sediment transport channel almost all particles passed through as there was no great reduction in turbidity levels. In contrast to burlap, linen has acceptable pore sizes, further proven from turbidity readings after both cross-flow filtration and perpendicular filtration in the sediment transport channel. Confirmation to this was also made from its sediment retention capacity, whereby the fabric was successful at retaining particles. The fabric also has a good tensile strength. Hence, linen will be used as the filter medium in the construction of the two stage cross-flow filter in future work.

\section{Conclusion}

After intense examination of the properties of fabric, linen is the selected filter medium. Though promising, more analysis of the various fabric types is to be performed to further confirm linen's capability for use as a filter medium. It will also be compared it to particle sizes and types deduced from sieve analysis. In addition, turbidity is to be investigated over a longer period of time to further examine turbidity levels of the Acono River during rainfall. To further enhance the research, the process of constructing a pilot scale two stage cross-flow filter has started. Filtration tests will be executed in which flow and turbidity will be varied, to further test linen. The investigations undertaken were successful and the results obtained are encouraging. 


\section{References}

[1] World Health Organization. 2017. "Water Quality and Health - Review of Turbidity: Information for Regulators and Water Suppliers." Accessed January 22, 2020. https://www.who.int/water_sanitation_health/publications/turbidity-information-200217.pdf.

[2] Fresh Outlook Foundation. 2020. "Water is a Basic Human Right!” Accessed January 22, 2020. https://freshoutlookfoundation.org/water-is-a-basic-human-right/.

[3] USGS. n.d. "Surface Runoff and the Water Cycle." Accessed December 6, 2019.

https://www.usgs.gov/special-topic/water-science-school/science/surface-runoff-and-water-cycle?qtscience_center_objects=0\#qt-science_center_objects.

[4] Watersheds. 2019. "Water Sources." Accessed December 6, 2019. http://www.waterresourcestt.com/.

[5] Water and Sewerage Authority of Trinidad and Tobago. 2008. "The Water Treatment Process." Accessed December 5, 2019. https://www.wasa.gov.tt/WASA_Education_water_WaterTreatment.html.

[6] Process Plant Operator. 2019. "Water Turbidity at the Acono Water Treatment Plant." Interview by Goldie Davis, September 20, 2019.

[7] Environmental Protection Agency, 1995. Water Treatment Manuals: Filtration. Environmental Protection

Agencyhttps://www.epa.ie/pubs/advice/drinkingwater/EPA_water_treatment_manual_\%20filtration1.pdf. [8] Ken Sutherland, 2008. Filters and Filtration Handbook. Fifth ed. Elsevier Ltd.

[9] Y El. Rayess, C. Albasi, P. Bacchin, P. Taillandier, J. Raynal, M. Mietton-Peuchot, A. Devantine. Crossflow Microfiltration Applied to Oenology: A Review. Journal of Membrane Science 382 nos. 1-2 (2011) 1-19. https://doi.org/10.1016/j.memsci.2011.08.008.

[10] Derek B. Purchas, Ken Sutherland, 2002. Handbook of Filter Media. Second Edition. Oxford: Elsevier Science Ltd.

[11] Environmental Protection Agency. 1995. Water Treatment Manuals: Filtration. Environmental Protection https://www.epa.ie/pubs/advice/drinkingwater/EPA_water_treatment_manual_\%20filtration1.pdf.

[12] Lawrence K Wang, Clint Williford, Wei-Yin Chen, 2004. "Fabric filtration." In Air Pollution Control Engineering, 59-95. Springer. https://link.springer.com/chapter/10.1007/978-1-59259-778-9_2.

[13] Murat Eyvaz, Serkan Arslan, Ercan Gurbulak, Ebubekir Yuksel, 2017. "Textile Materials in Liquid Filtration Practices: Current Status and Perspectives in Water and Wastewater Treatment." In Textiles for Advanced Applications, edited by Bipin Kumar and Suman Thakur, 293-320. IntechOpen https://www.intechopen.com/books/textiles-for-advanced-applications/textile-materials-in-liquidfiltration-practices-current-status-and-perspectives-in-water-and-wastew.

[14] AECOM. 2010. Environmental Impact Assessment: Establishment of a Regional Wastewater Collection System and Treatment Plant for San Fernando and Environs. https://www.wasa.gov.tt/Forms/EIAs/San\%20Fernando/CEC\%201567-

2006\%20San\%20Fernando\%20Wastewater\%20Project\%20-\%20Volume\%201\%20of\%20.pdf.

[15] Anwar Huq, Mohammed Yunus, Syed Salahuddin Sohel, Abbas Bhuiya, Michael Emch, Stephen P. Luby, Estelle Russek-Cohen, G. Balakrish Nair, R. Bradely Sack, Rita R. Colwell. Simple Sari Cloth Filtration of Water is Sustainable and Continues to Protect Villagers from Chlorea in Matlab, Bangladesh. The American Society for Microbiology 1 no.1, (2010) 1-5. https://mbio.asm.org/content/mbio/1/1/e0003410.full.pdf.

[16] World Health Organization. 2017. "Water Quality and Health - Review of Turbidity: Information for Regulators and Water Suppliers." Accessed January 22, 2020. https://www.who.int/water_sanitation_health/publications/turbidity-information-200217.pdf.

[17] Denver Fabrics. 2018. “About Linen Fabric.” Accessed June 28, 2019.

https://www.denverfabrics.com/pages/linen/linen-fabric-facts.aspx.

[18] A.J Halls. 1975. The Standard Handbook of Textiles. Newnes-Butterworths.

[19] Mitutoyo. 2013. "Surftest, SJ-400.” Accessed December 9, 2019.

https://www.mitutoyo.com/Images/003/308/2013_SJ-400.pdf. 
[20] Surface Roughness Terminology and Parameters. "Terminology.” Accessed December 9. https://www.predev.com/pdffiles/surface_roughness_terminology_and_parameters.pdf.

[21] Mulukutla, Mrinalini Sandip P. Harimkar, 2013. "Surface Properties Measurement." In Handbook of Measurement in Science and Engineering 2, edited by Myer Kutz, 1121-1149. New Jersey: John Wiley \& Sons.

[22] ImageJ. 2018. “ImageJ Features.” Accessed December 11, 2019. https://imagej.nih.gov/ij/features.html.

[23] E.A., Elnashar. Volume Porosity and Permeability in Double-Layer Woven Fabrics. AUTEX Research Journal 5 no.4 (2005): 207-218. http://www.autexrj.com/cms/zalaczone_pliki/4-05-4.pdf.

[24] Tinius Olsen. “Tensile.” Accessed December 10, 2019. https://www.tiniusolsen.com/testing/testtype/tensile-test.

[25] Hach. 1999. Model 2100N Laboratory Turbidimeter Instruction Manual for use with Software Version 1: Hach Company. https://www.hach.com/asset-get.download.jsa?id=10612025350.

[26] UMass Lowell. 2013. "Soil Grain Sizes" from 14.333 Geotechnical Laboratory Soil Classification. $\begin{array}{llll}\text { Accessed } & \text { January } & 2020 .\end{array}$ http://faculty.uml.edu/ehajduk/teaching/14.333/documents/14.3332013soilclassification.pdf.

[27] Armfield Limited, 1995. Instruction Manual Sediment Transport Channel S8 MkII, Issue 6. Armfield Limited.

[28] Murat Eyvaz, Serkan Arslan, Ercan Gurbulak, and Ebubekir Yuksel, 2017. "Textile Materials in Liquid Filtration Practices: Current Status and Perspectives in Water and Wastewater

Treatment." In Textiles for Advanced Applications, edited by Bipin Kumar and Suman Thakur, 293-320. IntechOpen. https://doi.org/10.5772/intechopen.69462. https://www.intechopen.com/books/textiles-foradvanced-applications/textile-materials-in-liquid-filtration-practices-current-status-and-perspectives-inwater-and-wastew.

[29] Canada Readers Digest Association, 1995. Complete Guide to Sewing Revised Edition. Readers Digest Association.

[30] Simon Crompton. 2019. "The Guide to Cloth: Weaves and Designs." Accessed December 7. https://www.permanentstyle.com/2017/01/the-guide-to-cloth-weaves-and-designs.html. 